\title{
Impact of climate change on runoff from a mid-latitude mountainous catchment in central Japan
}

\author{
Yoshinori Shinohara, ${ }^{1 *}$ Tomo'omi Kumagai, ${ }^{1}$ Kyoichi Otsuki, ${ }^{1}$ Atsushi Kume ${ }^{2}$ and Naoya Wada ${ }^{3}$ \\ ${ }^{1}$ Kasuya Research Forest, Kyushu University, Sasaguri, Fukuoka 811-2415, Japan \\ ${ }^{2}$ Ashoro Research Forest, Kyushu University, Ashoro-cho, Hokkaido 089-3705, Japan \\ ${ }^{3}$ Center for Far Eastern Studies, University of Toyama, Toyama 930-8555, Japan
}

\begin{abstract}
:
Hydrologic balance in high-altitude, mid-latitude mountain areas is important in terms of the water resources available to associated lowlands. This study examined how current and historical shifts in precipitation $(P)$ patterns and concurrent increases in temperature $(T)$ affected runoff $(Q)$ and other hydrologic components in a mid-latitude mountain catchment of central Japan, using a combination of long-term data and a simplified hydrologic model, along with their stochastic treatment. The availability of intensive meteorological and hydrological data from the period 1997-2001 allowed the derivation of key relationships for the current climate that tie the forcing term to the parameters or state variables. By using the data recorded in the period 1965-2001, the force for driving the historical simulation was generated. Based on this model and historical shifts in $P$ and $T$, the probability density functions of $Q(\operatorname{pdf}(Q))$ was computed. A main novelty in this study is that such a stochastic representation, which is useful for considering the influence of projected shifts in environmental factors on the hydrologic budget, was provided. Despite the large increase in the rate of $T$ in winter and spring, $\operatorname{pdf}(Q)$ in spring and summer varied appreciably during the time studied mainly because of an increase in snowmelt. An interannual change in whole-year $Q$ was robust to shifts in $T$ because while $Q$ in spring increased, in summer it decreased, implying a crucial effect of global warming on mountain hydrologic regimes is change in the timing of $Q$. Copyright $\odot 2009$ John Wiley \& Sons, Ltd.
\end{abstract}

KEY WORDS stochastic processes; greenhouse warming; water balance; snowmelt; snow hydrology; temperate forest

Received 16 April 2008; Accepted 5 January 2009

\section{INTRODUCTION}

The mean annual runoff $(Q)$ in mountainous areas is generally higher than that at lower altitudes in the same climatic regions because mountains receive more precipitation $(P)$ due to the orographic effect and lower temperatures $(T)$, resulting in lower transpiration (Zierl and Bugmann, 2005; Horton et al., 2006). Temporal water storage in the form of snow and ice also induces a delay in $Q$ (Kling et al., 2006). Therefore, mountainous areas play an important role in terms of water resources for lowlands. In particular, snowmelt water from mountainous areas contributes significantly to river runoff and water resources in many parts of the world (Hock et al., 2006).

The projected growth in atmospheric greenhouse gases within the coming century, as summarized by the Intergovernmental Panel on Climate Change report (IPCC) (Houghton et al., 2001), would significantly impact global and regional $T$ with concomitant modifications to $P$ patterns. This might result in profound influences on the hydrologic cycle in mountainous areas (McCarthy et al., 2001); for example, rainfall substituted for snowfall and earlier snowmelt in warmer winters (Knowles et al., 2006). As a result, a larger proportion of annual

* Correspondence to: Yoshinori Shinohara, Kasuya Research Forest, Kyushu University, 394 Tsubakuro, Sasaguri, Kasuya-gun, Fukuoka 811-2415, Japan. E-mail: shinohara@ forest.kyushu-u.ac.jp
$Q$ would occur in winter, with a smaller $Q$ in spring (Lettenmaier and Gan, 1990; Westmacott and Burn, 1997; Eckhardt and Ulbrich, 2003; Hodgkins et al., 2003; Findell and Delworth, 2005; Merritt et al., 2006). Hence, assessing their sensitivity to the potential shifts in global and regional $P$ and $T$ patterns is a necessary first step to managing future local and regional water resources (Arnell and Reynard, 1996; Jasper et al., 2004; Zierl and Bugmann, 2005; Horton et al., 2006).

What is less certain is an understanding of how current and historical climate changes have impacted hydrologic shifts in mid-latitude mountainous areas at high altitude, the subject of this investigation. As Whitaker and Sugiyama (2005) point out, temperate or maritime regions with mild temperatures, high humidity, winter rain and warm snowpack experience both accumulation and melt conditions concurrently, and thus the seasonal snowpack dynamics are different compared with colder boreal regions, where a number of field studies have reported the snow process (Hedstrom and Pomeroy, 1998; Lundberg and Koivusalo, 2003; Zhang et al., 2004). Furthermore, the coastal regions of central Japan along the Japan Sea, which are strongly influenced by coldair masses from Siberia in winter, receive some of the heaviest snowfall in the world (Ninomiya, 1968). However, long-term successive data that are necessary to detect the increase in winter $Q$ due to global change are lacking. 
Our aim is to investigate how hydrologic cycling of a mid-latitude forested and mountainous catchment in central Japan has responded to current and historical climate changes (i.e. $P$ and $T$ patterns). This work builds on an earlier study (Wada et al., 2004) that found that $T$ and winter $Q$ had significantly increased in a mid-latitude mountainous catchment in central Japan during the period from 1965 to 2001. In the present study, we go further and use current and historical $P$ and $T$ statistics represented in the manner of Kumagai et al. (2004a, 2004b), a simplified hydrological model described in Kondo et al. (1992) and Motoya et al. (2001), and meteorological and $Q$ data recorded in a mountainous area nature reserve within a heavy-snowfall region of central Japan (Wada et al., 2004) to address the study goals. We employ two types of data; daily records over a 5-year period (1997-2001), and monthly records over a 37-year period (1965-2001). The data were used to validate the model and to generate historical climate scenarios, respectively.

In this study, the hydrologic responses to the shifts in $P$ and $T$ statistics were represented as probabilistic descriptions, and this approach is thought to be useful for describing how the hydrologic budgets are altered by potential and projected shifts in environmental factors (Kumagai et al., 2004a, 2004b). Thus the framework used in this study will facilitate interpretations of how water budgets respond to future climate scenarios.

\section{STUDY SITE AND DATA}

While much of the site and a description of the monthly data obtained at the Kurobe Dam observatory were presented in Wada et al. (2004), a review and description of the daily and other observatories data are provided for completeness. In this study, we used two types of data sets, monthly data and daily data in the periods 1967-2001 and 1997-2001, respectively. In Japan, hydroelectric power companies own much of the longterm runoff from large area mountainous catchments and other related climatic data. Owing to their commercialism, they seldom provide the data to people even for scientific and environmental use. As a result, very few long-term high-resolution timescale (hourly or daily) data for large mountainous areas are available in Japan (Komatsu et al., 2007). Thus for the calculations in this study, while long-term monthly data (1967-2001) were available, only 5-year daily data (1997-2001) could be utilized.

The study site was the catchment area of the Kurobe Dam in Toyama prefecture, central Japan (Figure 1). The Kurobe Dam (186 m height and $429 \mathrm{~m}$ width), the biggest and the best-known dam in Japan, was established in 1963 by the Kansai Electric Power Company to make use of the exceptionally rich water resources of the Kurobe River to generate electric power. The catchment area is approximately $185 \mathrm{~km}^{2}$ and ranges from 1459 to $2997 \mathrm{~m}$ above sea level. Vegetation consists of various types of plants corresponding to the varying altitudes in the catchment area, i.e. spruce, Korean pine, hemlock fir, beech, and a great variety of alpine plants. Forest and alpine vegetation cover around $80 \%$ of the total catchment area, which has been conserved since 1934 when it was designated as a part of the Chubu-Sangaku National Park.

In this study, we used meteorological data obtained at the Kurobe Dam (KD; $1459 \mathrm{~m}$ above sea level, $36^{\circ} 34^{\prime} \mathrm{N}, 137^{\circ} 40^{\prime} \mathrm{E}$ ), and Kariyasu (KA; $1850 \mathrm{~m}$ a. s. 1.) and Kumonodaira (KU; $2576 \mathrm{~m}$ a. s. 1.) observatories (Figure 1). At the $\mathrm{KD}$, a daily maximum $T\left(T_{\max }\right)$ and minimum $T\left(T_{\min }\right)$ thermometer $(\mathrm{SV}-101$, Ishihara Ondokei, Tokyo, Japan) and daily rain gauge with a heater for both rainfall and snowfall (RH-5, Ikeda Keiki, Tokyo, Japan) were installed on the roof of the damcontrol building. In addition, the daily $Q$ was measured at the head gate of the dam using a water gauge (QWP8-104D, Meisei Denki, Tokyo, Japan). Note that this $Q$ observation cannot be influenced by the draw-off and water-level control of the dam. At KA and KU, daily $P$ in the form of rainfall has been measured. In the model calculations, the catchment area was divided into four zones (W1-W4), classified by their altitudes, i.e. W1: 1467-1800 m, W2: 1800-2200 m, W3: 2200-2600 m, and W4: $2600-2977 \mathrm{~m}$. We assumed that the $P$ at KD, KA and KU represented $P$ in $\mathrm{W} 1, \mathrm{~W} 2$, and both $\mathrm{W} 3$ and W4, respectively. Daily $T_{\max }$ and $T_{\min }$ in each of $\mathrm{W} 1-\mathrm{W} 4$ was estimated using assumed temperature lapse rate $\left(0.65^{\circ} \mathrm{C}\right.$ per $\left.100 \mathrm{~m}\right)$, measured $T$ at $\mathrm{KD}$ and the averaged altitude of each zone. For model testing, we used daily time series of $P, T$ and $Q$ at $\mathrm{KD}$ and $P$ at KA and KU, measured during the period 1997-2001.

In our model simulations for historical climate changes, monthly average data obtained at the KD during the period 1965-2001 were available and so were used to construct historical climate scenarios. For the $P$ data at KA and KU in period 1965-2001 we used daily $P$ at $\mathrm{KD}\left(P_{-\mathrm{KD}}\right)$, KA $\left(P_{-\mathrm{KA}}\right)$ and $\mathrm{KU}\left(P_{-\mathrm{KU}}\right)$ for $1997-2001$, and then proceeded to derive relationships between daily $P_{-\mathrm{KD}}$ and $P_{-\mathrm{KA}}$ and $P_{-\mathrm{KU}}$. Here, averaged $P_{-\mathrm{KA}}$ and $P_{-\mathrm{KU}}$

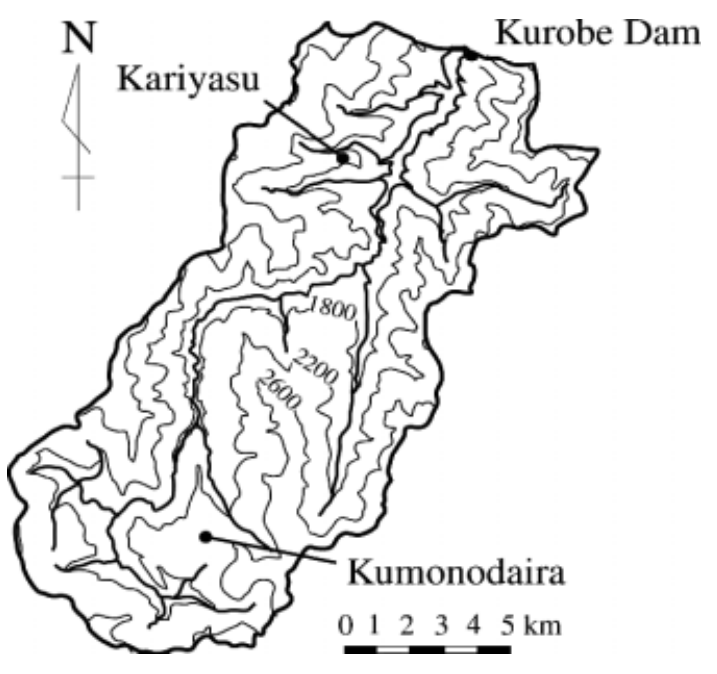

Figure 1. The catchment area in the upper part of the Kurobe Dam, Toyama, central Japan 
were computed in bins of $P_{-\mathrm{KD}}$ (increments of 10) and a regression model describing $P_{-}$KD and bin-averaged $P_{-}$KA and $P_{-\mathrm{KU}}$ were derived $\left(P_{-\mathrm{KA}}=1.44 P_{-\mathrm{KD}}, R^{2}=0.96\right.$; $\left.P_{\mathrm{KU}}=1.16 P_{\mathrm{KD}}, R^{2}=0.94\right)$. Using these equations, $P_{-} \mathrm{KA}$ and $P_{-} \mathrm{KU}$ for $1965-2001$ were calculated from $P_{-\mathrm{KD}}$ for $1965-2001$.

The mean annual $P_{-}$KD for the period 1965-2001 was $3002 \mathrm{~mm}$ with major seasonal variations. For example, the mean $P_{-\mathrm{KD}}$ for June-August (JJA) was $1024 \mathrm{~mm}$ and for March-May (MAM) it was $609 \mathrm{~mm}$. For the period 1997-2001, the mean monthly number of precipitation days ranged from 10 in October 1999, April and July 2001 to 27 in January 2001 . The mean annual $T_{\max }$ and $T_{\min }$ were 9.8 and $2.5^{\circ} \mathrm{C}$, respectively. While the mean $T_{\max }$ and $T_{\min }$ for JJA were 20.9 and $13.2^{\circ} \mathrm{C}$, respectively, for December-February (DJF) they were -1.7 and $-7.9^{\circ} \mathrm{C}$, respectively.

Wada et al. (2004) suggested that overall trends in 1965-2001 at KD show significant increases in mean $T_{\max }$ and $T_{\min }$ for all seasons, and the seasonal total $Q$ for DJF (significant at the $P=0.01$ level), while there are no significant trends in the other factors (Figure 2). In their analyses, mean increasing rates of $T_{\max }$ and $T_{\min }$ per decade range from 0.50 (JJA) to 0.68 (DJF) and from 0.30 (JJA) to 0.62 (MAM), respectively (Table I). It is noteworthy that the increasing trend in annual mean $T$ at KD correlates well with each of those at other meteorological observatories around $\mathrm{KD}$ over period 1965-2001; a consistently rising $T$ occurred in this region (Wada et al., 2004).

\section{METHODOLOGY}

First, we discuss development, parameterization, and validation of the hydrological model. We then proceed to discuss its use for assessing shifts in $Q$ following current and historical shifts in $P$ and $T$ statistics.

Our hydrological model consists of three submodels: (1) a model for evapotranspiration; (2) an energy balance model for snow-melt and -accumulation; and (3) a model for $Q$. Infiltration (i.e. $P$ and snowmelt minus interception) and evapotranspiration are computed using submodels (1) and (2) at each W1-W4 zone, and are then area-weighted averaged to supply water into the submodel (3), which is lumped with W1-W4. It should also be noted that discriminating $P$ into rainfall and snowfall was crucial in our model; we used the determinant temperature as a function (Hasemi, 1991), given by

$$
T_{\text {cr }}=4.0-0.44 \ln H
$$

where $T_{\mathrm{cr}}$ is the critical temperature at which $P$ is defined as rainfall or snowfall with a probability of 0.5 , and $H$ is the altitude. $T_{\text {cr }}$ was determined using averaged $H$ in each of the W1-W4 zones. In this study, all $P$ values were assumed to be rainfall when $T>T_{\mathrm{cr}}$, and snowfall when $T \leq T_{\text {cr. }}$. All model results were interpreted on a daily time scale.
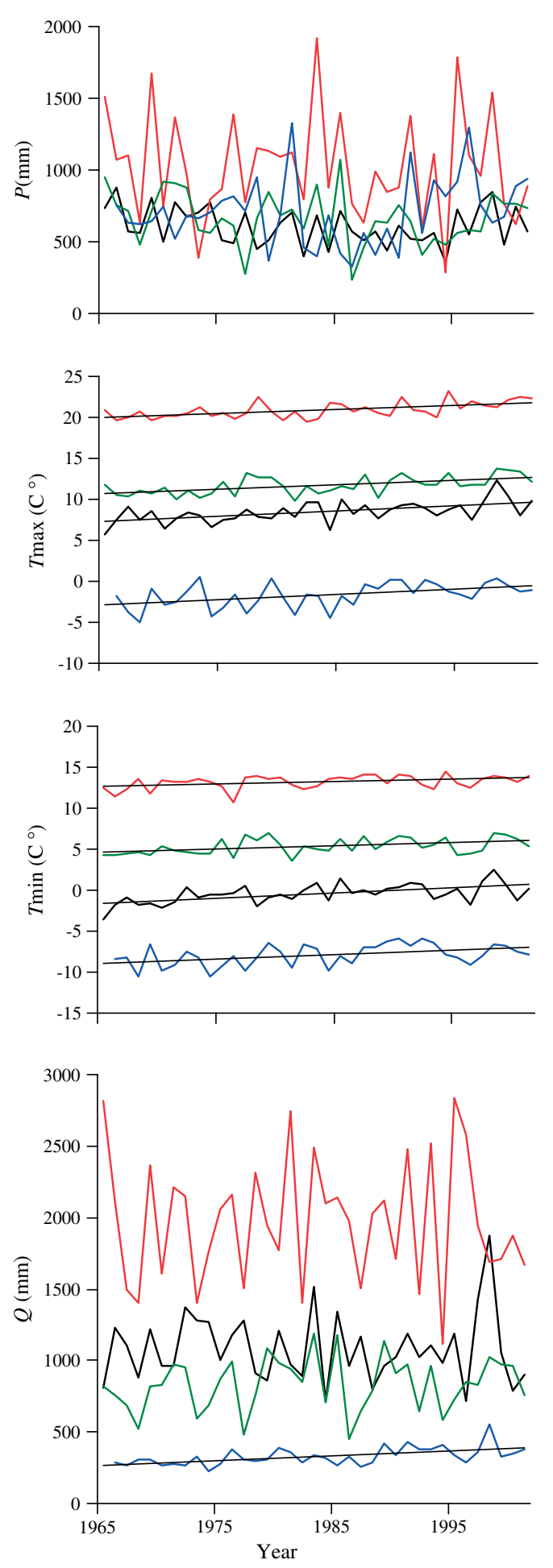

Figure 2. Interannual variations of seasonal climatic and hydrological factors (December-February (DJF), blue line; March-May (MAM), black line; June-August (JJA), red line; September-November (SON), green line) for the 37 years between 1965 and 2001 in Kurobe, Toyama, central Japan. Reading from the top: seasonal precipitation $(P)$, seasonal mean daily maximum temperature $\left(T_{\max }\right)$ and minimum temperature $\left(T_{\mathrm{min}}\right)$, and seasonal runoff $(Q)$. Solid lines denote significant linear trends (Wada et al., 2004)

To validate the model, the 1997-2001 was used; however, for simulations for current and historical climates, 1965-2001, only monthly average data were available 
Table I. Mean increasing rates of daily maximum $\left(T_{\max }\right)$ and minimum temperature $\left(T_{\min }\right)$ per decade in each season over 1965-2001, analysed using a linear regression model (Wada et al., 2004)

\begin{tabular}{lcccc}
\hline & DJF & MAM & JJA & SON \\
\hline$T_{\max }\left({ }^{\circ} \mathrm{C} /\right.$ decade $)$ & 0.68 & 0.67 & 0.50 & 0.57 \\
& $(0 \cdot 22)$ & $(0 \cdot 16)$ & $(0.12)$ & $(0.14)$ \\
$T_{\min }\left({ }^{\circ} \mathrm{C} /\right.$ decade $)$ & 0.55 & $0 \cdot 62$ & 0.30 & 0.38 \\
& $(0.19)$ & $(0 \cdot 15)$ & $(0.11)$ & $(0.15)$ \\
\hline
\end{tabular}

DJF, December-February; MAM, March-May; JJA, June-August; SON, September-November. Standard errors are shown in parentheses.

thereby necessitating a stochastic treatment. The generation of stochastic $P$ and $T$ time series are also discussed. Again, Wada et al. (2004) investigated the shifts in $Q$ and $T$ in 1965-2001 using the monthly data, and therefore the model using the daily-based data in this study enabled us to analyse them more in detail.

\section{Evapotranspiration modelling}

Forest rainfall interception $\left(I_{\mathrm{c}}\right)$ stores are considered to be fully lost to evaporation, with the remainder reaching the soil as throughfall and stemflow. Forest evapotranspiration $\left(E_{\mathrm{T}}\right)$, the sum of the losses resulting from tree transpiration and evaporation from the soil, is governed by different mechanisms. Thus we consider them separately as follows.

Since there was considerable $P$ in the study area, the primary forcing variable for $E_{\mathrm{T}}$ was radiative energy. Daily $E_{\mathrm{T}}$ was computed using a radiation-based Makkink formula (de Bruin and Stricker, 2000), theoretically synonymous with the Priestley and Taylor (1972) expression, given by

$$
E_{\mathrm{T}}=\beta\left(a \frac{\Delta}{L_{\mathrm{v}}(\Delta+\gamma)} R_{\mathrm{s}}+b\right)
$$

where $a$ and $b$ are the constant parameters, $\Delta$ is the rate of change of saturation water vapour pressure with temperature, $L_{\mathrm{v}}$ is the latent heat of vaporization of water, $\gamma$ is the psychrometric constant, and $R_{\mathrm{S}}$ is the daily solar radiation. The limiting factor, $\beta$, is a function of the time and $T$, related to a growing season length, i.e. the canopy duration and transpiration period, which were defined by Yoshifuji et al. (2006). When monthly average temperature is $>5^{\circ} \mathrm{C}$, the month is assumed to be in the growing season and the value of $\beta$ is estimated using a sinusoid (Kondo et al., 1992), whereas when the monthly average temperature is $\leq 5^{\circ} \mathrm{C}$, the month is assumed to be in dormant season and $\beta$ is determined to be 0 .

In this study, $R_{\mathrm{S}}$ was obtained as a product of the atmospheric transmissivity $\tau_{t}$ and the potential extraterrestrial solar radiation calculated geometrically using the day of the year and the longitude and latitude of the site. The formulation and parameterization of $\tau_{t}$ as a function of $T_{\max }-T_{\min }$ was described by Bristow and Campbell (1984) and its applicability to some regions in Japan was identified by Shinohara et al. (2007):

$$
\tau_{t}=\kappa_{1}\left\lfloor 1-\exp \left(-\kappa_{2} \Delta T^{\kappa_{3}}\right)\right\rfloor
$$

where $\Delta T$ is the daily range of $T\left(T_{\max }-T_{\min }\right)$, and $\kappa_{1}$, $\kappa_{2}$ and $\kappa_{3}$ are the empirical parameters. $\kappa_{2}$ was calculated using the function $\Delta T$ proposed by Bristow and Campbell (1984). The values of $\kappa_{1}(=0.75)$ and $\kappa_{3}(=2.3)$ were determined by fitting calculation results to measurements at Toyama Meteorological Station located around $40 \mathrm{~km}$ northwest of the Kurobe Dam. The Makkink formula was applied to a number of regions throughout Japan, and parameters $a$ and $b$ in the studied area were taken to be 0.851 and 0.13 , respectively (Nagai, 1993). Note that thermodynamic variables, e.g. $\Delta$ and $L_{\mathrm{v}}$, were calculated based on daily mean $T$ as a value averaged between $T_{\max }$ and $T_{\min }$.

Daily $I_{\mathrm{c}}$ was implemented in the piecewise model proposed by Kondo et al. (1992):

$$
I_{\mathrm{c}}=\left\{\begin{array}{cl}
E_{\mathrm{Tpot}}+S, & \text { for } \quad \Omega P \geq E_{\mathrm{Tpot}}+S_{\mathrm{max}} \\
\Omega P, & \text { for } \Omega P<E_{\mathrm{Tpot}}+S_{\max }
\end{array}\right.
$$

where $E_{\text {Tpot }}$ is the evaporation rate from a wet surface, $S$ is the water stored on the canopy, related to its maximum value $S_{\max }$ and $P$, and $\Omega$ is the probability of the contact of rainfall on the canopy. $E_{\text {Tpot }}$ is obtained using Equation (2) for $\beta=1$ and taking into consideration the duration of the rain event $(\zeta)$. $\Omega$ was calculated using the degree of canopy closure, the leaf inclination factor and the leaf area index. $I_{\mathrm{c}}$ was assumed to occur in the day when rainfall occurs, and the proportion of $E_{\mathrm{T}}$ and $I_{\mathrm{c}}$ within a day depends on $\zeta$ related to $P$. Parameters necessary for computing Equation (4) in the studied area are given in Kondo et al. (1992).

Snowfall interception, as well as transpiration and rainfall interception, is also a key factor for considering water balance in a snowy forested region (e.g. Lundberg and Halldin, 2001). However, it was ignored in our hydrological model because neglecting snowfall interception may cause only an insignificant error in runoff estimates in the studied catchment for two reasons: (1) in general, snowfall interception in deciduous broad-leaved forest is less than 5\% of snowfall (Lundberg et al., 2004), and about $40 \%$ of the catchment area is covered with deciduous broad-leaved forest (Shimamura et al., 2003); and (2) dwarf stone pine dominates at altitudes between 2200 and $2800 \mathrm{~m}$ above sea level in this region (Shidei, 1963), and this species grows to less than $3 \mathrm{~m}$, so they were completely covered with snow.

\section{Snow-melt and-accumulation modelling}

Snow-accumulation, i.e. snowpack water equivalent $\left(S_{\mathrm{W}}\right)$ at the present time step, was described by adding precipitation in the form of snowfall to $S_{\mathrm{W}}$ at the former time step.

Assuming that soil and snowpack heat storage can be neglected, surface snowmelt (SS) can be expressed using the energy balance model proposed by Walter et al. (2005):

$$
\begin{gathered}
\left(1-a_{\mathrm{L}}\right) R_{\mathrm{S}}+\varepsilon_{\mathrm{a}} \sigma T^{4}+c_{\mathrm{w}} P T-\varepsilon_{\mathrm{S}} \sigma T_{\mathrm{S}}^{4} \\
=L_{\mathrm{f}} \Delta S_{\mathrm{W}}+\rho c_{\mathrm{p}} C_{\mathrm{H}} U\left(T_{\mathrm{S}}-T\right) \\
\quad+L_{\mathrm{v}} \rho C_{\mathrm{E}} U\left(q_{\mathrm{sat}}\left(T_{\mathrm{S}}\right)-q\right)
\end{gathered}
$$


where $a_{\mathrm{L}}$ is the surface albedo, $\varepsilon_{\mathrm{a}}$ and $\varepsilon_{\mathrm{S}}$ are the long wave emissivity of atmosphere and snow, respectively, $\sigma$ is the Stefan-Boltzmann constant, $c_{\mathrm{w}}$ is the heat capacity of water, $T_{\mathrm{S}}$ is the surface temperature, $L_{\mathrm{f}}$ is the latent heat of fusion, $\Delta S_{\mathrm{W}}$ is the change in $S_{\mathrm{W}}, \rho$ is the density of air, $c_{\mathrm{p}}$ is the specific heat of air at constant pressure, $C_{\mathrm{H}} U$ and $C_{\mathrm{E}} U$ are the instant exchange speeds of sensible and latent heat fluxes, respectively, $q$ is the specific humidity of air, and $q_{\mathrm{sat}}\left(T_{\mathrm{S}}\right)$ is the saturation value at $T_{\mathrm{S}}$. Note that in this study $C_{\mathrm{E}} U$ was assumed to be identical to $C_{\mathrm{H}} U$.

$a_{\mathrm{L}}$ can be expressed as a function of $T$ (Yamazaki et al., 1994; Suizu, 2002), given by:

$$
a_{\mathrm{L}}=\left\{\begin{array}{c}
a_{\mathrm{MAX}}, \\
\text { for snowy day } \\
\left(a_{0}-0 \cdot 4\right) \exp (-1 / k)+0 \cdot 4 \\
\text { for non - snowy day }
\end{array}\right.
$$

in which

$$
a_{\mathrm{MAX}}= \begin{cases}-0 \cdot 12 T+0 \cdot 76, & \text { for } T>-1 \cdot 0^{\circ} \mathrm{C} \\ 0.88, & \text { for } T \leq-1 \cdot 0^{\circ} \mathrm{C}\end{cases}
$$

and

$$
k=\left\{\begin{array}{cl}
4 \cdot 0, & \text { for } T \geq 0 \cdot 1{ }^{\circ} \mathrm{C} \\
-4 \cdot 9 T+4 \cdot 5, & \text { for } \quad T<0 \cdot 1{ }^{\circ} \mathrm{C}
\end{array}\right.
$$

where $a_{\mathrm{MAX}}$ is the maximum surface albedo, $a_{0}$ is the surface albedo on the previous day, which is related to the number of days since snowfall events, and $k$ is an empirical parameter. The parameterization of $\varepsilon_{\mathrm{a}}$ as a function of $T$ is described by Campbell and Norman (1998).

$P$ in Equation (5) is a precipitation in the form of rainwater: if the rainwater has the same temperature as $T$, and heat is added to the snowpack by lowering the temperature of the rainwater to freezing point, $0{ }^{\circ} \mathrm{C}$ (Walter et al., 2005). Since Equation (5) was used to simulate the SS, $\varepsilon_{\mathrm{S}}$ and $T_{\mathrm{S}}$ were set to 0.97 (Kondo and Yamazawa, 1986) and $0{ }^{\circ} \mathrm{C}$, respectively. Note that we confirmed there was little impact of the constant $T_{S}(=$ $0{ }^{\circ} \mathrm{C}$ ) on $Q$ estimates despite the appreciable variation in $T_{S}$. In addition, $q$ was assumed to be $q_{\mathrm{sat}}(T)$ in this study.

For a snow surface, $C_{\mathrm{H}} U$ can be expressed using the empirical function of wind speed $U$ proposed by Kondo and Xu (1997)

$$
C_{H} U=0.001+0.002 \times 0.7 U
$$

In the study area, the average $U$ in the March and April 'snowmelt season' ranges from 5.1 to $8.2 \mathrm{~m} \mathrm{~s}^{-1}$ with wind blowing from a prevailing westerly direction (Toyama Prefecture, 1976). Given the constant average wind speed $\left(\approx 6.7 \mathrm{~m} \mathrm{~s}^{-1}\right)$ and the effect of the tree density on the wind attenuation (described later), $C_{\mathrm{H}} U$ was assumed to be $0.006 \mathrm{~m} \mathrm{~s}^{-1}$ in this study. It should be noted that Walter et al. (2005) reported that assuming constant wind speed introduced relatively little error into the SS predictions.

Finally, because the constant ground snowmelt (SG; $\Delta S_{\mathrm{W} \_ \text {bot }}$ ) was expected to dominate a major part of $Q$ from the study area in the mid-winter season (Kurashima et al., 1999; Whitaker and Sugiyama, 2005), it was necessary to resolve how environmental factors affect the SG. The SG occurs by heat exchange between the ground surface and bottom of the snowpack, and $\Delta S_{\mathrm{W} \_b o t}$ decreases with a decrease in ground temperature. Therefore, $\Delta S_{\mathrm{W}_{-} \text {bot }}$ takes a maximum value at the commencement of the snow season, and then gradually decreases with time. Since very few studies of the SG have been published, we made an attempt to model it using the results from some technical reports and our $Q$ measurements; a linear function $\Delta S_{\mathrm{W} \_b o t}=2.5-0.007 X$ (where $X$ is the number of days after commencement of snowaccumulation) was derived to tune the computed $Q$ in the mid-winter and snowmelt seasons to the measured ones.

A large part of the study area is covered with forest and alpine vegetation, which apparently impact on snowmelt processes (Ohta, 1994; Hedstrom and Pomeroy, 1998; Lundberg and Halldin, 2001; Storck et al., 2002). In particular, the differences in $R_{s}$ and $U$ between open and forested areas might cause a larger difference in snowmelt processes than differences in other meteorological factors do (Link and Marks, 1999). Taking this line, Suzuki et al. (1999) obtained linear relationships between $R_{s}$ and $U$ in open and in sparse/dense forest areas. Taking their results into consideration, $R_{s}$ and $U$ were assumed to be multiplied by the factors 0.6 and 0.5 for the snowmelt calculation (Equation (5)) in this study. In addition, Suzuki et al. (1999) pointed out that downward long-wave radiation in a forested area was different from that in an open area. However, because the relationship between downward long-wave radiations in the two areas was weaker than those of other meteorological factors (i.e. $R_{s}$ and $U$ ) and the variation in observed long-wave radiation was smaller than that in $R_{s}$, we assumed that the difference in long-wave radiation between open and forested areas could be ignored in the calculation in this study.

\section{Runoff modelling}

A lumped runoff model, the so-called bucket model, proposed by Kondo et al. (1992) was used as a simple representation of the $Q$ response to potential shifts in climatic factors. Neglecting detailed information on the properties of soil moisture dynamics, two soil moisture zones (i.e. two buckets) were considered, the water storages of which follows the water balance equations:

$$
W_{\mathrm{A}}=W_{\mathrm{A} 0}+d W_{\mathrm{A}}-E_{\mathrm{T}}
$$

and

$$
W_{\mathrm{B}}=W_{\mathrm{B} 0}+d W_{\mathrm{B}}-Q_{\text {base }}
$$

in which

$$
d W_{\mathrm{A}}=\left(W_{\mathrm{Amax}}-W_{\mathrm{A} 0}\right)\left[1-\exp \left(-P^{\prime} / W_{\mathrm{Amax}}\right)\right]
$$

and

$$
\begin{aligned}
d W_{\mathrm{B}}= & \left(W_{\mathrm{B} \max }-W_{\mathrm{B} 0}\right) \\
& {\left[1-\exp \left\{-\left(P^{\prime}-d W_{\mathrm{A}}\right) / W_{\mathrm{B} \max }\right\}\right] }
\end{aligned}
$$


where $W_{\mathrm{A}}$ and $W_{\mathrm{B}}$ are the water storages in the upper (bucket A) and the lower (bucket B) soil moisture zones, respectively, $W_{\mathrm{A} 0}$ and $W_{\mathrm{B} 0}$ are the values at the previous time step, $d W_{\mathrm{A}}$ and $d W_{\mathrm{B}}$ are the increases in water storages in buckets $\mathrm{A}$ and $\mathrm{B}$, respectively, $Q_{\text {base }}$ is the baseflow from bucket B, described as a product of a constant parameter $k_{\text {base }}$ and $W_{\mathrm{B} 0}$, while $W_{\text {Amax }}$ and $W_{\text {Bmax }}$ are the water storage capacities of buckets $\mathrm{A}$ and $\mathrm{B}$, respectively, and $P^{\prime}$ is the rate of precipitation infiltrating into the ground (i.e. $P-I_{\mathrm{c}}+$ $\left.\Delta S_{\mathrm{W}}+\Delta S_{\mathrm{W} \_ \text {bot }}\right)$. Thus daily $Q$ can be described as

$$
Q=P^{\prime}-d W_{\mathrm{A}}-d W_{\mathrm{B}}+Q_{\mathrm{base}}
$$

The parameters $k_{\text {base }}$ and $W_{\text {Amax }}$ were specified in accordance with Kondo et al. (1994), and $W_{\text {Bmax }}$ was estimated to fit the calculated $Q$ to the observed $Q$ during the period from July to September because there was less snowpack effect on $Q$ in this period in the studied catchment.

\section{Simulations of climatic factors}

After generating current and historical time series of climatic factors, those of $Q$ from the study catchment can be computed. From the simulated time series of $Q$, the statistics for it during the period 1965-2001 can be calculated. We then examined shifts in the statistics of $Q$ based on these estimated historical changes in the climatic (or forcing) factors.

It is necessary to first construct the $P$ time series because they are needed to construct other climatic factors. Current and historical $P$ time series were constructed as series of random numbers generated according to probability distributions representing the $P$ characteristics in this area. The temporal structure within each $P$ event was ignored and the marked Poisson process representing $P$ was physically interpreted at a daily time scale, where the pulse of $P$ correspond to daily $P$ assumed to be concentrated at an instant in time (Rodriguez-Iturbe et al., 1999; D'Odorico et al., 2000; Laio et al., 2001; Porporato et al., 2002; Kumagai et al., 2004a, 2004b). The frequency and number of $P$ events may be assumed to be stochastic variables with an interval between $P$ events, $\tau$, expressed as an exponential distribution given by

$$
f_{\mathrm{T}}(\tau)=\lambda \exp (-\lambda \tau), \quad \text { for } \tau \geq 0
$$

where $1 / \lambda$ is the mean interval times. The amount of $P$ when $P$ occurs is also assumed to be an independent random variable, expressed by exponential probability density function:

$$
f_{\mathrm{H}}(h)=-\frac{1}{\eta} \exp \left(-\frac{1}{\eta} h\right), \quad \text { for } h \geq 0
$$

where $\eta$ is the mean depth of rainfall events.

First, using 1997-2001 data and probability distribution functions (15) and (16), we evaluated the stochastic parameters $\lambda$ and $\eta$, representing monthly $P$ characteristics at this area. These monthly parameters were related to the monthly total amount of $P$ in each of the rainfall and snowfall seasons through linear regression models $(\lambda=0.5$ (no significant trend) and $\eta=0.05 P+0.45\left(R^{2}=0.85\right)$ for a rainfall season, and $\lambda=0.0009 P+0.45\left(R^{2}=0.55\right)$ and $\eta=0.03 P+0.96$ $\left(R^{2}=0.71\right)$ for a snowfall season). These equations were then applied to the monthly $P$ time series in 1965-2001, and thus we could obtain a daily $P$ time series in the period 1965-2001 as random numbers generated from Equations (15) and (16) representing $P$ distribution characteristics for each month during 1965-2001.

It is logical to expect that $P$ changes led to radiation environment changes and increased or decreased cloud cover, resulting in $T$ changes. Also, $T$ is expected to be the most critical factor for modelling snowmelt $Q$ here (Figure 2). Thus a relationship between $T$ and $P$ needs to be developed to assess how climatic factor (i.e. $P$ and $T$ ) patterns altered the water budget. We constructed a daily $T$ time series for the period 1965-2001 using the following procedures: (1) The determined daily $P$ time series in the period 1965-2001 was separated into the periods 1965-1974 (scenario 1974), 1975-1984 (scenario 1984), 1985-1994 (scenario 1994), and 1995-2004 (scenario 2004). (2) Gaussian representing the distributions of the daily mean values of $T$ and $T_{\max }-T_{\min }$ in each bin range of $P(P=0,0<P \leq 10,10<P)$ were obtained for each month during 1997-2001. To obtain elevated regional $T$ in each scenario and each season, a new mean of the daily $T$ in the distribution was found by adding the product of the mean increasing rate of $T$ per decade (Table I) and the year of the scenario (e.g. 1974 for scenario 1974) minus 1964 to the initial mean. (3) From those Gaussian distributions, a time series of $T$ and $T_{\max }-T_{\min }$ related to those of $P$ in each scenario and each season were generated as random numbers.

As a result, we obtained the scenarios 1974, 1984, 1994 and 2004 as current and historical climatic scenarios. Before discussing current and historical water budget simulations, we next evaluate the reproductive skills of our hydrological model.

\section{MODEL RESULTS}

\section{Validation of the hydrological model}

Given the total amount of $P$ during the specific period $\left(P_{\text {period }}\right)$, the relationship between $\eta$ and $\lambda$ (Kumagai et al., 2004a, 2004b) is

$$
P_{\text {period }}=D_{\text {period }} \eta \lambda
$$

where $D_{\text {period }}$ is the number of days in the period. If we use both of the linear regression models for estimating $\eta$ and $\lambda$ (constructed in the previous section), the relationship between them, i.e. Equation (17), might not be obeyed. Thus we investigated three methods for estimating $\eta$ and $\lambda$, as follows: both linear regression models describing $\eta$ and $\lambda$ were used (a). $\lambda$ was determined using the linear regression model, and $\eta$ was calculated from Equation (17) and the $\lambda$ determined here (b), and vice 
versa (c). Figure 3 compares the monthly total $P$ calculated from these three methods with the measurements. $P$ calculated using method (c) best reproduced the measurements in a root-mean squared sense. Calculations using method (a) increased the scatter between measured and modelled $P$, and especially, underestimates the measurements for large $P$. Also, when method (b) was used, the scatter was still large compared with using method (c). These results imply that setting $\lambda$ to a constant value for the rainfall season in methods (a) and (b) might cause the scattering because $\lambda$ fluctuated in the rainfall season during 1997-2001. Hence, method (c) appears the best and has accordingly been adopted throughout.

The hydrograph derived from measured $P$ and $T$ values is compared against measurements for 1997-2001 in Figure 4. The model well reproduces measured $Q$ despite all the simplifying assumptions. Figure 5 further compares calculated $Q$ against measurements, but here, observed $Q$ was discriminated for the four seasons because the $Q$ responses to the forms of rainfall and snowfall/snowpack were anticipated to be different.

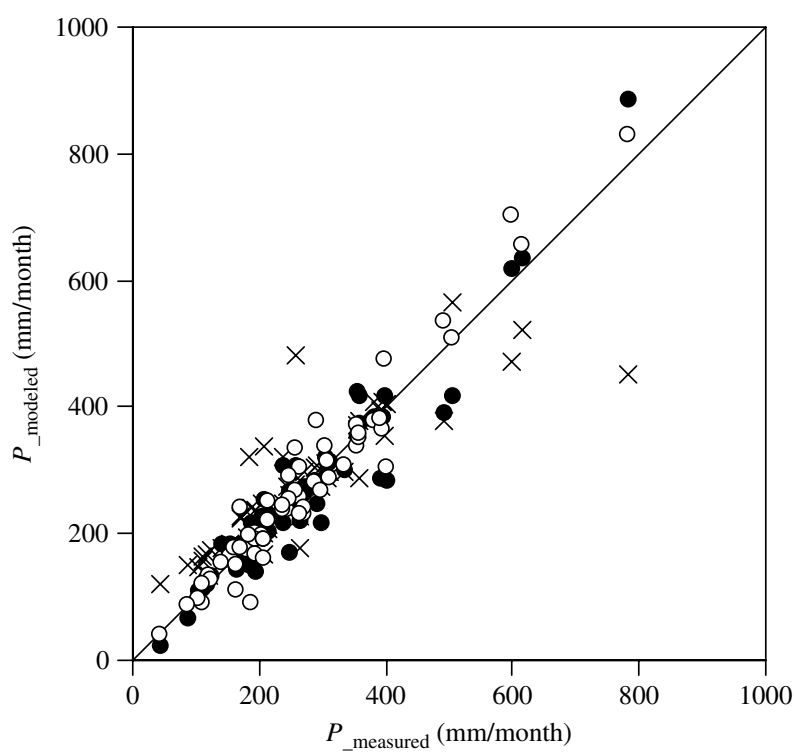

Figure 3. Comparison between measured $(P$ measured $)$ and modelled monthly total precipitation ( $P$ _modeled $)$ during the period 1997-2001. $P_{\text {_modeled }}$ were calculated by methods (a; cross), (b; solid circle) and (c; open circle) (see Section 4.1. for details)

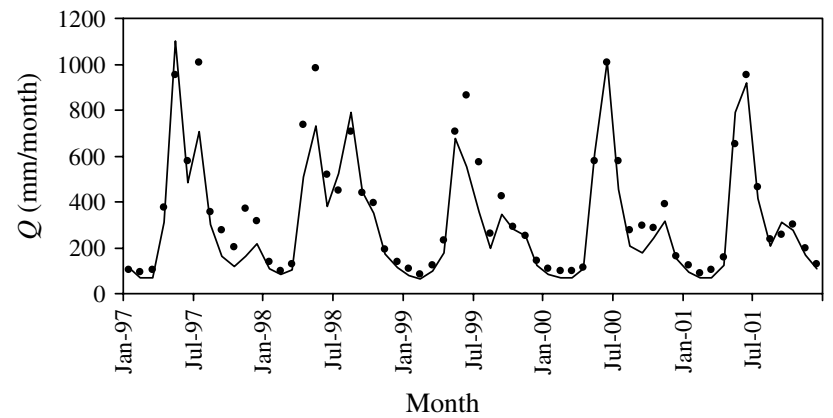

Figure 4. Comparison between measured (solid circle) and modelled (line) monthly runoff $(Q)$ during the period 1997-2001

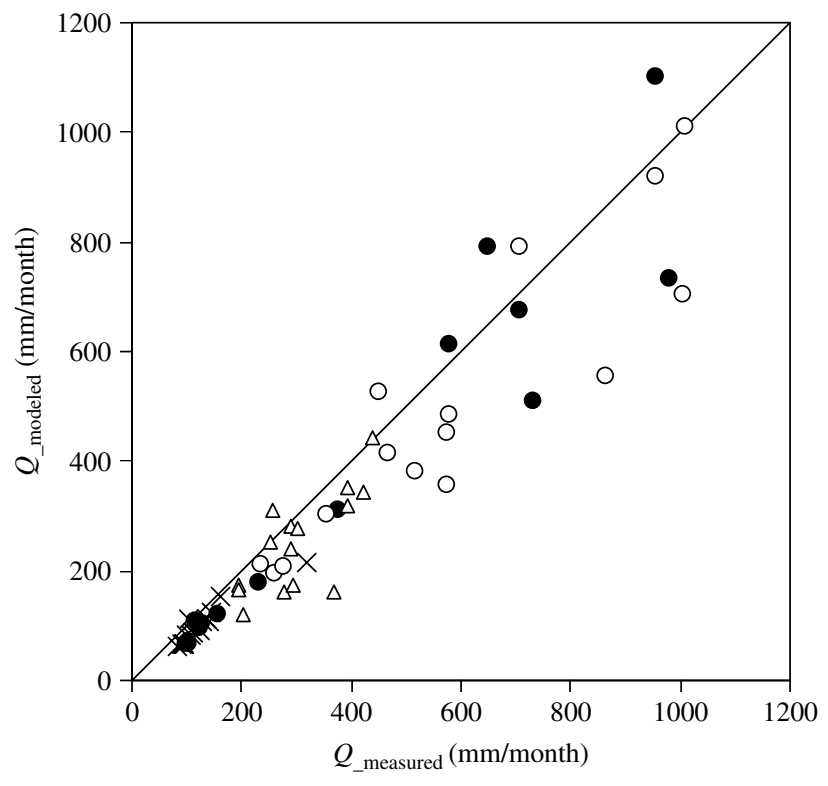

Figure 5. Comparison between measured $\left(Q_{\text {_measured }}\right)$ and modelled monthly total runoff ( $Q_{\text {_modeled }}$ ) during the period 1997-2001. Cross, DJF; solid circle, MAM; open circle, JJA; triangle, SON (see Figure 2)

Given that the current and historical climatic statistics are provided at seasonal timescales, it is instructive to compare how well the measured and modelled probability distribution functions of $Q(\operatorname{pdf}(Q))$ agree during 1997-2001 for all four seasons (Figure 6). The comparisons between modelled and measured $\operatorname{pdf}(Q)$ suggest that the model surprisingly well reproduces seasonal dynamics in $\operatorname{pdf}(Q)$. However, there are small departures in Figure 6c (JJA); large $Q$ more frequently occurs in summer. Hence, the model showed a slight tendency to underestimate the measurements, especially for large $Q$ (Figure 5); probably because of underestimation of catchment area-averaged precipitation caused by its large spatial variation or/and the model's overestimation of catchment water loss (i.e. $E_{\mathrm{T}}$ plus $I_{\mathrm{c}}$ ) in summer. In addition, we should note that wind might affect the accuracy of $P$ observations, which generally results in their underestimation especially in snowy season. However, considering that snowmelt in spring is much larger than snowmelt in the other seasons, that most of the snowmelt is induced by heavy snowfall in the preceding season and that the systematic $Q$ underestimates were not seen in spring (see Figures 4, 5 and 6b), we were able to ignore the effect of wind in this study.

\section{Water balance for current and historical climatic scenarios}

The reproductions of $P$ and $Q$ are important because much of $P$ is reserved as snowpack, and the sum of $E_{\mathrm{T}}$ and $I_{\mathrm{c}}$ does not play an important role in the water balance in this catchment (details described later). Thus it is necessary to compare how well measured and modelled $P$ and $Q$ for the current and historical scenarios agree (Figure 7).

Since the way in which shifts in $T$ are described in our hydrological model is most critical for applications such 

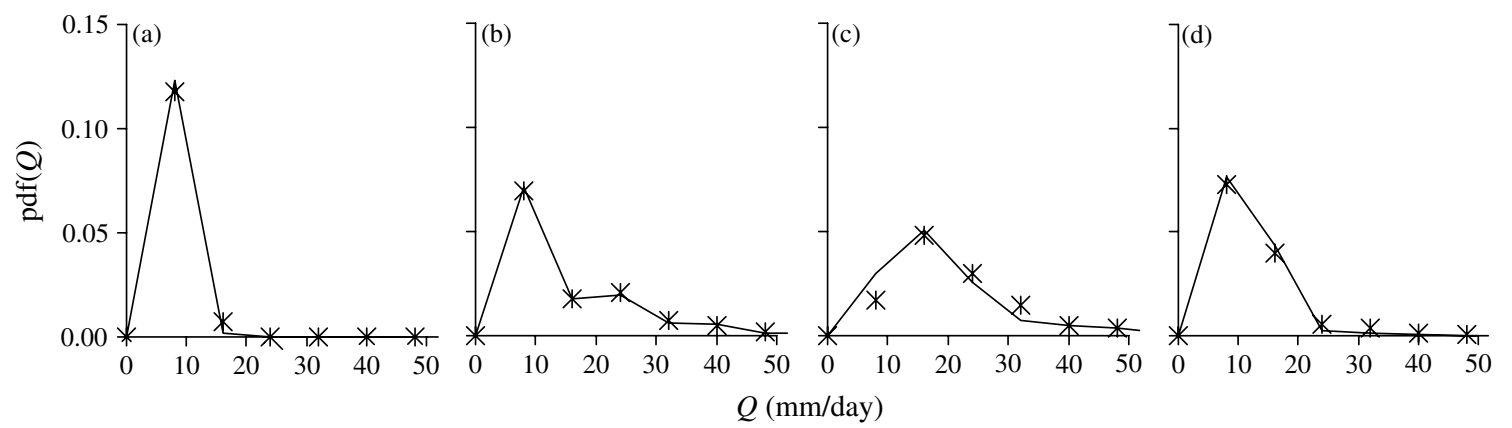

Figure 6. Probability density functions of runoff $(\operatorname{pdf}(Q))$ for 1997-2001, estimated from actual runoff data (asterisk) and calculated by the model (line). (a) DJF, (b) MAM, (c) JJA, and (d) SON (see Figure 2)
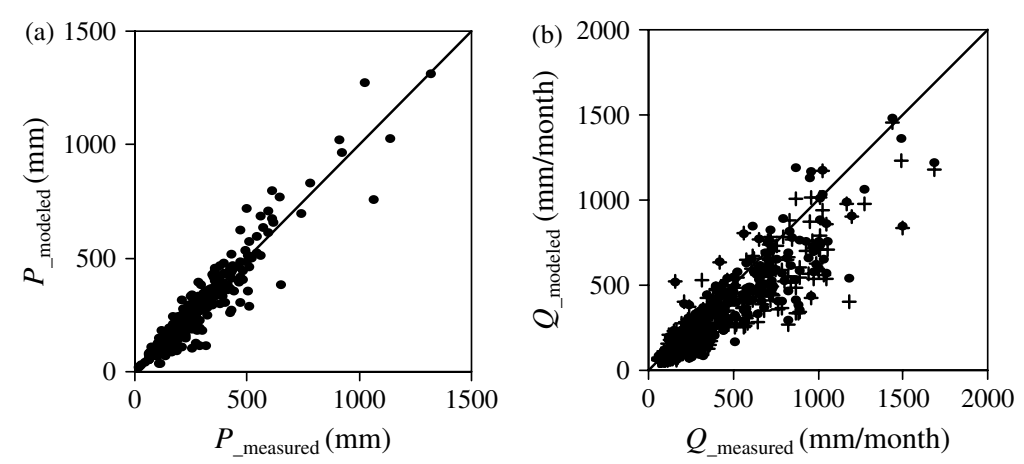

Figure 7. Comparisons between measured and modelled (a) monthly total precipitation ( $P_{\text {_measured }}$ and $P_{\text {_modeled }}$, respectively) and (b) monthly total runoff ( $Q_{- \text {measured }}$ and $Q_{\text {_modeled, }}$, respectively) for the 1965-2001. $Q_{\text {_modeled }}$ was calculated using the method used earlier (solid circle) and the Ornstein-Uhlenbeck process (cross) (See sections Simulation of Climate factors and Water balance for current and historical climatic scenarios for details)

as the assessment of the impact of climate change, an appropriate framework to generate the daily $T$ field must be developed. Thus we also investigated an alternative to assuming a random distribution of Gaussian $T$ increments generated from $P$ correlations (discussed earlier). The widely used Ornstein-Uhlenbeck process (Taylor and Karlin, 1998), is given by

$$
\begin{aligned}
T-T_{\_\mathrm{mo}}= & \left(T_{0}-T_{\_\mathrm{mo}}\right) \exp \left(-\alpha \_ \text {mo } t\right) \\
& +\frac{\sigma_{T} \exp \left(-\alpha_{\_ \text {mo }} t\right)}{\sqrt{2 \alpha_{\_\mathrm{mo}}}} B_{\mathrm{R}} \\
& {\left[\exp \left(2 \alpha \_ \text {mo } t\right)-1\right], \text { for } t \geq 0 }
\end{aligned}
$$

in which

$$
\sigma_{T}=\sigma_{T \_ \text {mo }} \sqrt{\frac{2 \alpha_{\_} \mathrm{mo}}{1-\exp \left(-2 \alpha_{\_} \mathrm{mo} t\right)}}
$$

where $T_{\text {mo }}$ is the monthly average daily $T, T_{0}$ is the initial $T$ of the month, $\alpha_{-}$mo is the monthly drift coefficient describing an exponentially decreasing trend toward the origin, $t$ is the day of the month, $\sigma_{T}$ is the diffusion parameter represented by the standard deviation of daily $T$ in the month, $\sigma_{T-m o}$, and $B_{\mathrm{R}}$ is the standard Brownian motion. Note that the parameters $T_{-}$mo,$\alpha_{-}$mo and $\sigma_{T \_ \text {mo }}$ were obtained for each of 12 months in the study period 1997-2001. Unlike the method used in Section 3.4, this framework is independent of $P$ and assumes the distribution of times when $T$ regresses to a certain standard value as the appropriate random variable. Figure $7 \mathrm{~b}$ also compares the measured monthly $Q$ for 1965-2001 with those calculated using the above two methods, indicating which one appears to best reproduce the measured $Q$ (root-mean-squared error: 134.2 vs. $149.1 \mathrm{~mm} \mathrm{month}^{-1}$ ).

The monthly averaged hydrographs computed using the scenarios 1974, 1984, 1994 and 2004 are compared in Figure 8. While there were no differences in $Q$ for August-March between all the scenarios, behaviors of $Q$ for the scenarios 1994 and 2004 differed from those for the scenarios 1974 and 1984 during the other months. From the former study period (the scenarios 1974 and 1984) to the latter period (the scenarios 1994 and 2004), $Q$ in April and May appreciably increased, and also, $Q$ in June and July, when it peaks in the year, were significantly reduced.

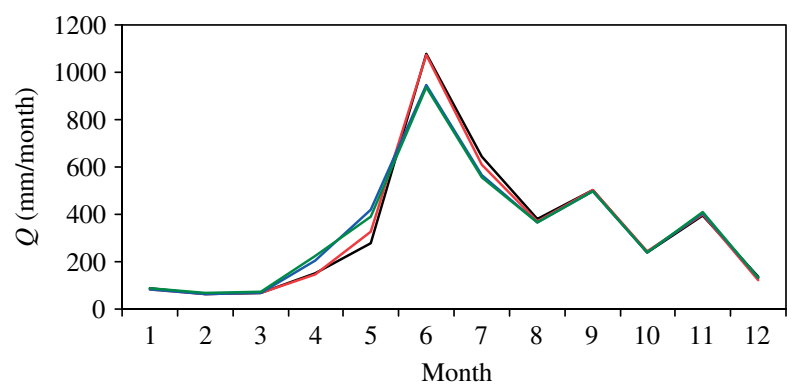

Figure 8. Comparisons of monthly runoff $(Q)$ for the scenarios 1974 (black line), 1984 (red line), 1994 (blue line), and 2004 (green line) 
Furthermore, the water balance components of the scenarios 1974, 1984, 1994 and 2004 for each of the four seasons are summarized in Table II. As the current and general hydrologic status, we found that $Q$ were much less than $P$ in DJF and MAM, and especially in DJF, the majority of $P$ (more than $500 \mathrm{~mm}$ ) was reserved as snowpack. The MAM $Q$ was likely to be a compound made up of the $Q$ from the snowpack in DJF and MAM and the $Q$ of rainfall in MAM. While $Q$ crucially surpassed $P$ in JJA due to snowmelt $Q$ from the snowpack accumulated in the previous season; while in $\mathrm{SON}$, each hydrologic component was almost balanced. $E_{\mathrm{T}}$ occurred only in the growing seasons and was extremely low because of low $T$ in the study catchment, which is located at the high altitude. The annual total of the sum of $E_{\mathrm{T}}$ and $I_{\mathrm{c}}$ did not reach $400 \mathrm{~mm}$.

In DJF, from scenarios 1984 to 2004, $Q$ increased by about $20 \mathrm{~mm}$ due to increases in the SG. In MAM, from scenarios 1974 to 2004 , increases in snowmelt $Q$ in the first half of MAM increased $Q$ by about $200 \mathrm{~mm}$. Because of this increase in snowmelt $Q$, the $Q$ in JJA was significantly reduced from scenarios 1974 to 2004 .

Table II. Seasonal and annual water balance for all four scenarios

\begin{tabular}{lrrrrr}
\hline & Scenario & $P(\mathrm{~mm})$ & $E_{\mathrm{T}}(\mathrm{mm})$ & $I_{\mathrm{c}}(\mathrm{mm})$ & $Q(\mathrm{~mm})$ \\
\hline DJF & 1974 & 814 & 0 & 1 & 284 \\
& 1984 & 814 & 0 & 1 & 264 \\
& 1994 & 814 & 0 & 1 & 277 \\
\multirow{4}{*}{ MAM } & 2004 & 814 & 0 & 1 & 288 \\
& 1974 & 726 & 0 & 34 & 494 \\
& 1984 & 726 & 0 & 38 & 538 \\
& 1994 & 726 & 0 & 46 & 687 \\
JJA & 2004 & 726 & 0 & 48 & 680 \\
& 1974 & 1305 & 49 & 157 & 1873 \\
& 1984 & 1305 & 57 & 159 & 1823 \\
& 1994 & 1305 & 59 & 157 & 1650 \\
SON & 2004 & 1305 & 59 & 158 & 1632 \\
& 1974 & 827 & 9 & 76 & 713 \\
& 1984 & 827 & 9 & 78 & 720 \\
& 1994 & 827 & 12 & 82 & 719 \\
Year Total & 2004 & 827 & 13 & 84 & 722 \\
& 1974 & 3690 & 58 & 267 & 3363 \\
& 1984 & 3690 & 66 & 276 & 3346 \\
& 1994 & 3690 & 71 & 284 & 3333 \\
& 2004 & 3690 & 72 & 292 & 3323 \\
\hline
\end{tabular}

$P$ : precipitation, $E_{\mathrm{T}}:$ evapotranspiration, $I_{\mathrm{c}}:$ rainfall interception, $Q$ : runoff.
In JJA, $E_{\mathrm{T}}$ changed little, and thus contributed little to $Q$. Hence, in JJA, decreases in snowmelt $Q$ appreciably altered $Q$. On both annual and seasonal timescales, $E_{\mathrm{T}}$ and $I_{\mathrm{c}}$ increased over the scenarios due to increasing $T$, but they did not alter the shifts in $Q$ in MAM and JJA. Again, shifts in $E_{\mathrm{T}}$ and $I_{\mathrm{c}}$ were not crucial for a shift in $Q$, but snowmelt affected by increasing $T$ significantly altered it. It is interesting to note that on annual timescales some partial cancellation emerged; i.e. from scenarios 1974 to 2004 the $Q$ in DJF and MAM increased, and these increases contributed to a reduction in $Q$ in JJA. Hence, year total $Q$ appears more robust to historical shifts in $T$, despite the slight decreases due to increases in $E_{\mathrm{T}}$ and $I_{\mathrm{c}}$.

\section{Stochastic representations of runoff from the scenarios}

Ensemble seasonal and annual probability distributions of $Q(\operatorname{pdf}(Q))$ for the scenarios 1974, 1984, 1994 and 2004 are compared in Figure 9. General features of seasonal and annual $\operatorname{pdf}(Q)$ are as follows:

DJF: In most cases $Q$ is around $3 \mathrm{~mm} \mathrm{day}{ }^{-1}$, derived from the SG.

MAM: The canonical structure of $\operatorname{pdf}(Q)$ is a bimodal distribution reflecting the 'two-states' of $Q$, i.e. either large from the SS and rainfall, or small from the SG.

JJA: $Q$, derived from snowmelt in the early part of JJA and rainfall, are distributed in a wide range; the highest $\operatorname{pdf}(Q)$ does not reach $0 \cdot 1$.

SON: Most $Q$ is from rainfall and is around $8 \mathrm{~mm} \mathrm{day}^{-1}$.

Whole year: The canonical structure of $\operatorname{pdf}(Q)$ is a bimodal distribution. The lower $Q\left(3 \mathrm{~mm} \mathrm{day}^{-1}\right)$ tail is mainly due to the SG in DJF and MAM, while the upper $Q\left(8 \mathrm{~mm} \mathrm{day}{ }^{-1}\right)$ tail comes mainly from the rainfall in SON. It is important to understand the high frequency of the SG in the whole year $Q$ distribution. It should be noted that because the total amount of JJA $Q$ is about a half of the year total $Q$ (Table II), the large and low frequency $Q$ in JJA have great contributions to the year total $Q$.

The changes in $P$ and $T$ statistics did not significantly alter $\operatorname{pdf}(Q)$ in DJF and SON (Figure 9a, d), but did in MAM and JJA (Figure 9b, c). In MAM, because of the increases in $Q$ from the SG in scenarios 1984-2004, lower $Q$ tails appreciably increase in scenarios 1974-2004. Also, the upper $Q$ tail in scenario 1974
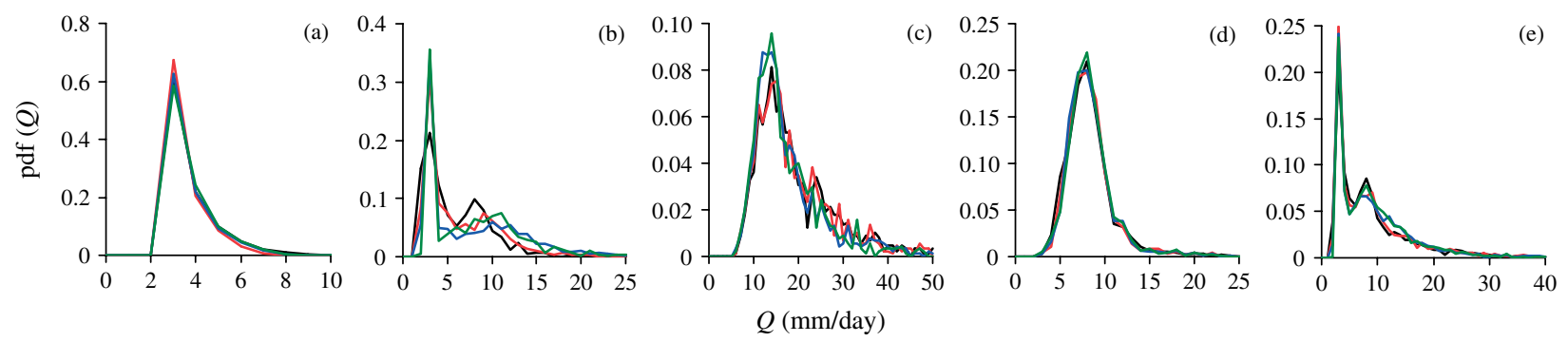

Figure 9. Probability density functions of runoff $(Q)$, for the scenarios 1974 (black line), 1984 (red line), 1994 (blue line), and 2004 (green line). (a) DJF, (b) MAM, (c) JJA, (d) SON, and (e) whole year (see Table II) 
shifts to a higher $Q$ with time because of increases in the SS from scenarios 1974 to 2004. Note that this results in an increase in total $Q$ in MAM over time (Table II). In JJA, the snowpack was reduced in the first half of the season due to an increase in MAM $Q$ from the SS, and low $Q\left(10-20 \mathrm{~mm} \mathrm{day}^{-1}\right)$ increased and high $Q$ (>20 mm day ${ }^{-1}$ ) decreased from scenarios 1974 to 2004. Consequently, the total amount of $Q$ in JJA decreased over the course of time (Table II).

As a result, the $Q$ for the total year experienced little change for all scenarios because increases in $Q$ for MAM were compensated for by decreases in JJA (Figure 9e). However, we should note that the climatic shifts somewhat levelled the upper $Q$ tail, and accordingly increased the contribution of high $Q$ to the total amount.

\section{DISCUSSION AND CONCLUSIONS}

A previous study (Wada et al., 2004) investigated how historical shifts in snowmelts resulting from an increase in global and regional $T$ affected the $Q$ from a midlatitude mountain area of central Japan using meteorological and hydrological data recorded over the 37 years from 1965 to 2001, along with their statistical analyses. In the present study, we have examined how the estimated historical shifts in $P$ patterns and concurrent increases in $T$ affected the $Q$ from that mountain area using a combination of long-term data, a simplified hydrological model and associated stochastic treatments. We developed a lumped runoff model combined with forest evapotranspiration and snow-melt and snow-accumulation models. These consider aspects of their spatial distributions within the study catchment. The availability of intensive meteorological and hydrological data, i.e. the 1997-2001 data set, allowed us to test our model and to derive key relationships for the current climate that tie the forcing term to parameters or state variables. For example, the meteorological data were used to derive relationships between monthly $P$ and stochastic parameters describing daily $P$ (for both forms of rainfall and snowfall), between $P$ and variability in $T$, and between $P$ and the runoff parameters. In turn, these relationships were related to the long-term monthly climate data (i.e. the 1965-2001 data set), and generated the force that drove the historical simulation.

There are few significant $P$ shifts for this region in 1965-2001 compared with the current scenario. Nevertheless, we assumed that the $T$ patterns obtained by relating it to $P$ showed a constantly increasing trend (see Table I). In fact, Wada et al. (2004) confirmed that the increasing trend in $T$ observed in the study area was valid, and that its rate was the highest among other observations made in lower and urban areas. Furthermore, their analyses revealed that only winter $Q$ significantly increased during the period 1965-2001 and that a variation in $T$ has more influence on the $Q$ time course than one in $P$.

However, because there were considerable interannual variations in seasonal $P$, especially in JJA (Figure 2), and some interactions between plural climatic factors (e.g. $P$ and $T$ ) might affect the water balance components, we thought it difficult to abstract the effect of greenhouse warming on the $Q$ shifts. Furthermore, hydrological responses in the future or any projected climate scenarios should not be presented as deterministic representations such as a hydrograph because input data in such scenarios cannot avoid having variations and as a result, neither can calculated outputs. Kumagai et al. (2004a, 2004b) successfully used a mechanistic model with stochastic treatments, and by probability representations, clarified how the hydrologic budgets are altered by projected shifts in climatic factors. It should be noted that this stochastic framework was also used successfully to understand potential shifts in the hydrologic balance responding to climate change in this snowy study catchment.

Although the increasing rate of $T$ was high in winter and spring, $\operatorname{pdf}(Q)$ in MAM and JJA varied appreciably over the course of time. In DJF, the total amount of $Q$ was relatively small, and shifts in $\operatorname{its} \operatorname{pdf}(Q)$ can be submerged in each interval of the $x$ axis. Therefore, any increasing trend for $Q$ in winter as Wada et al. (2004) reported might not have been detected in this study. In MAM, increased $\mathrm{SS}$, a major part of total snowmelt $Q$, resulting from an increase in $T$, induced the shifts in total $Q$. In this study, an increase in $Q$ in MAM increased contributions to low $Q$ in JJA, because the snowpack for snowmelt in JJA had already been consumed in MAM. This simulation result can be thought of as reasonable when considering that in general, the snowpack completely disappears in September in this study catchment.

Projected changes in $Q$ regimes using some future climate scenarios in the European Alps suggest consistent conclusions, i.e. enhancing winter $Q$, reducing summer $Q$, and shifting snowmelt-induced peak flows to earlier dates (Zierl and Bugmann, 2005). Thus the effect of greenhouse warming on the historical hydrologic regimes detected in this study could assist in predicting and examining future trends. On the other hand, an interannual change in whole-year $Q$ was robust to shifts in $T$ because while $Q$ in MAM increased, in JJA it decreased. Here, we emphasize that one key effect of global warming on mountain hydrologic regimes is changes in the timing of $Q$, as Zierl and Bugmann (2005) have also pointed out. We need to pay careful attention to this change in the timing of $Q$, especially with regard to its many socioeconomic aspects. Increased $Q$ in spring will enhance the risk of avalanches and floods. Reduced summer $Q$ will affect the availability of water resources for city water and agricultural uses. Again, note that although whole-year total $Q$ is least impacted by projected shifts in $T$, reservoir management will have to adapt to projected changes in $Q$ (Zierl and Bugmann, 2005).

This study primarily focused on $T$ shifts and their propagation through snowmelt flow and reservoirs in the form of snowpack and soil infiltration; however, to predict future water balances, $P$ changes induced by global warming effects need to be considered. For example, Déry et al. (2005) examined pan-Arctic climate connectivity between Eurasian snow cover extent 
and Canadian snow water equivalent, suggesting future increase/decreases in river discharges from two basins in Canada. The 21st century Northern Hemisphere snow cover extent, frequency and mass has been explored using a global climate model and the IPCC Special Report on Emission Scenarios (Déry and Wood, 2006). Hence, to track and predict the precise effects of enhanced $T$ on mountainous hydrology, further research that utilizes extensive and technically difficult experiments will be required.

\section{ACKNOWLEDGMENTS}

We express our sincere thanks to the Kansai Electric Power Company for providing data recorded by the meteorological observatories in the Kurobe Dam-catchment area. This study was in part supported by a grant from the Ministry of Education, Sports, Culture and Technology of Japan (No. 17380096). We would like to thank Dr Hikaru Komatsu for useful critique.

\section{REFERENCES}

Arnell NW, Reynard NS. 1996. The effects of climate change due to global warming on river flows in Great Britain. Journal of Hydrology 183: 397-424. DOI: 10·1016/0022-1694(95)02950-8.

Bristow KL, Campbell GS. 1984. On the relationship between incoming solar radiation and daily maximum and minimum temperature. Agricultural and Forest Meteorology 31: 159-166. DOI: 10.1016/0168-1923(84)90017-0.

Campbell GS, Norman JM. 1998. An Introduction to Environmental Biophysics, 2nd edn. Springer: New York.

de Bruin HAR, Stricker JNM. 2000. Evaporation of grass under nonrestricted soil moisture conditions. Hydrological Sciences Journal 45 : $391-406$.

Déry SJ, Wood EF. 2006. Analysis of snow in the 20th and 21st century geophysical fluid dynamics laboratory coupled climate model simulations. Journal of Geophysical Research 111: D19113. DOI: 10.1029/2005JD006920.

Déry SJ, Sheffield J, Wood EF. 2005. Connectivity between Eurasian snow cover extent and Canadian snow water equivalent and river discharge. Journal of Geophysical Research 110: D23106. DOI: 10.1029/2005JD006173.

D’Odorico P, Ridolfi L, Porporato A, Rodriguez-Iturbe I. 2000. Preferential states of seasonal soil moisture: the impact of climate fluctuations. Water Resources Research 36: 2209-2219.

Eckhardt K, Ulbrich U. 2003. Potential impacts of climate change on groundwater recharge and streamflow in a central European low mountain range. Journal of Hydrology 284: 244-252. DOI: 10.1016/j.jhydrol.2003.08.005.

Findell KL, Delworth TL. 2005. A modeling study of dynamic and thermodynamic mechanisms for summer drying in response to global warming. Geophysical Research Letters 32: L16702. DOI: 10.1029/2005GL023414.

Hasemi T. 1991. On a relation between probability occurrence of solid precipitation and ground air temperature (1) -on the locality of the relation and possibility of prediction of precipitation type-. Journal of Japanese Society of Snow and Ice 53: 33-43 (in Japanese with English summary).

Hedstrom N, Pomeroy J. 1998. Measurements and modeling of snow interception in the boreal forest. Hydrological Processes 12: $1611-1625$

Hock R, Ress G, Williams MW, Ramirez E. 2006. Preface: contribution from glaciers and snow cover to runoff from mountains in different climates. Hydrological Processes (Special Issue) 20: 2089-2090. DOI: 10.1002/hyp.6206.

Hodgkins GA, Dudley RW, Huntington TG. 2003. Changes in the timing of high river flows in New England over the 20th century. Journal of Hydrology 278: 244-252. DOI: 10·1016/S0022-1694(03)00155-0.
Horton P, Schaefli B, Mezghani A, Hingray B, Musy A. 2006. Assessment of climate-change impacts on alpine discharge regimes with climate model uncertainty. Hydrological Processes 20: 2091-2109. DOI:10·1002/hyp.6197.

Houghton JT, Ding Y, Griggs DJ, Noguer M, van der Linden PJ, Xiaosu D (eds). 2001. Climate Change 2001: The Scientific Basis. Cambridge University Press; New York.

Jasper K, Calanca P, Gyalistras D, Fuhrer J. 2004. Differential impacts of climate change on the hydrology of two alpine river basins. Climate Research 26: 113-129.

Kling H, Fürst J, Nachtnebel HP. 2006. Seasonal, spatially distributed modelling of accumulation and melting of snow for computing runoff in a long-term, large-basin water balance model. Hydrological Processes 20: 2141-2156. DOI: 10·1002/hyp.6203.

Knowles N, Dettinger MD, Cayan DR. 2006. Trends in snowfall versus rainfall in the western United States. Journal of Climate 19: 4545-4559.

Komatsu H, Kume T, Otsuki K. 2007. Contemporary role of catchment water balance data for forest evaporation research. Journal of the Japanese Forest Society 89: 346-359 (in Japanese with English summary).

Kondo J, Nakajima T, Watanabe T. 1994. A study of forest evapotranspiration restraint due to the soil water content. Journal of Japan Society of Hydrology and Water Resources 7: 402-410 (in Japanese with English summary)

Kondo J, Watanabe T, Nakazono M. 1992. Heat budget evaluation of forest evapotranspiration in Japan. Tenki 39: 685-695 (in Japanese).

Kondo J, Xu JQ. 1997. Seasonal variations in heat and water balances for non-vegetated surfaces. Journal of Applied Meteorolgy 36: 1676-1695.

Kondo J, Yamazawa H. 1986. Measurement of snow surface emissivity. Boundary Layer Meteorology 34: 415-416.

Kumagai T, Katul GG, Porporato A, Saitoh TM, Ohashi M, Ichie T, Suzuki M. 2004a. Carbon and water cycling in a Bornean tropical rainforest under current and future climate scenarios. Advances in Water Resources 27: 1135-1150. DOI: 10·1016/j.advwatres.2004-10·002.

Kumagai T, Katul GG, Saitoh TM, Sata Y, Manfroi OJ, Morooka T, Ichie T, Kuraji K, Suzuki M, Porporato A. 2004b. Water cycling in a Bornean tropical rain forest under current and projected precipitation scenarios. Water Resources Research 40: W01104. DOI: 10.1029/2003WR002226.

Kurashima E, Seki M, Kato T, Mukaida Y. 1999. Proposal and estimation of a simulation method for snowmelt near the ground -a study of bottom snowmelt (1). Transactions of the Japanese Society of Irrigation, Drainage and Rural Engineering 201: 33-41 (in Japanese with English summary).

Laio F, Porporato A, Ridolfi L, Rodriguez-Iturbe I. 2001. Plants in water-controlled ecosystems: active role in hydrologic processes and response to water stress, II. Probablistic soil moisture dynamics. Advances in Water Resources 24: 707-723. DOI: 10·1016/S03091708(01)00005-7.

Lettenmaier DP, Gan TW. 1990. Hydrologic sensitivities of the Sacramento-San Joaquin river basin, California, to global warming. Water Resources Research 26: 69-86.

Link T, Marks D. 1999. Distributed simulation of snowcover massand energy-balance in the boreal forest. Hydrological Processes 13: 2439-2452.

Lundberg A, Halldin S. 2001. Snow interception evaporation. Review of measurement techniques, processes and models. Theoretical and Applied Climatology 70: 117-133.

Lundberg A, Koivusalo H. 2003. Estimating winter evaporation in boreal forests with operational snow course data. Hydrological Processes 17: 1479-1493. DOI: 10·1002/hyp.1179.

Lundberg A, Nakai Y, Thunehed H, Halldin S. 2004. Snow accumulation in forests from ground and remote-sensing data. Hydrological Processes 18: 1941-1955. DOI: 10·1002/hyp.1459.

McCarthy JJ, Canziani OF, Leary NA, Dokken DJ, White KS (eds). 2001. Climate Change 2001: Impacts, Adaptation, and Vulnerability. Contribution of Working Group II to the Third Assessment Report of the Intergovernmental Panel on Climate Change. Cambridge University Press: Cambridge.

Merritt WS, Alila Y, Barton M, Taylor B, Cohen S, Neilsen D. 2006. Hydrologic response to scenarios of climate change in sub watersheds of the Okanagan basin, British Columbia. Journal of Hydrology 326: 79-108. DOI: 10·1016/j.jhydro.2005 $10 \cdot 025$.

Motoya K, Yamazaki T, Yasuda N. 2001. Evaluating the spatial and temporal distribution of snow accumulation, snowmelts and discharge in a multi basin scale: an application to the Tohoku Region, Japan. Hydrological Processes 15: 2101-2129. DOI: 10·1002/hyp.279. 
Nagai A. 1993. Estimation of pan evaporation by Makkink equation. Journal of Japan Society of Hydrology and Water Resources 6: 238-243 (in Japanese with English summary).

Ninomiya K. 1968. Heat and water budget over the Japan Sea and the Japan Islands in winter season. Journal of the Meteorological Society of Japan 46: 343-372.

Ohta T. 1994. A distributed snowmelt prediction model in mountain areas based on an energy balance method. Annals of Glaciology 19: $107-113$.

Porporato A, D’Odorico P, Laio F, Ridolfi L, Rodriguez-Iturbe I. 2002. Ecohydrology of water-controlled ecosystems. Advances in Water Resources 25: 1335-1348. DOI: 10·1016/S0309-1708(02)00058-1.

Priestley CHB, Taylor RJ. 1972. On the assessment of surface heat flux and evaporation using large-scale parameters. Monthly Weather Review 100: $81-92$.

Rodriguez-Iturbe L, Porporato A, Ridolfi L, Isham V, Cox DR. 1999. Probabilistic modeling of water balance at a point: the role of climate, soil and vegetation. Royal Society of London Proceedings Series A 455: 3789-3805.

Shidei T. 1963. Productivity of haimatsu (Pinus pumila) community growing in alpine zone of Tateyama-Range. Journal of the Japanese Forest Society 45: 169-173 (in Japanese with English summary).

Shimamura Y, Izumi Y, Nakayama D, Matsuyama H. 2003. Estimation of snow water equivalent and snowmelt water using the snow index - a case study in the Kurobe Basin. Journal of Japan Society of Hydrology and Water Resources 16: 331-348 (in Japanese with English summary).

Shinohara Y, Komatsu H, Otsuki K. 2007. A method for estimating global solar radiation from daily maximum and minimum temperature: its applicability to Japan. Journal of Japan Society of Hydrology and Water Resources 20: 462-469 (in Japanese with English summary).

Storck P, Lettenmaier DP, Bolton SM. 2002. Measurement of snow interception and canopy effects on snow accumulation and melt in a mountainous maritime climate, Oregon, United States. Water Resources Research, 38: W01223. DOI: 10·1029/2002WR001281.

Suizu S. 2002. A snowmelt and water equivalent snow model applicable to an extensive area. Journal of Japanese Society of Snow and Ice 64: 617-630 (in Japanese with English summary).
Suzuki K, Ohta T, Kojima A, Hashimoto T. 1999. Variations in snowmelt energy and energy balance characteristics with larch forest density on Mt Iwate, Japan: observations and energy balance analyses. Hydrological Processes 13: 2675-2688.

Taylor HM, Karlin S. 1998. An Introduction to Stochastic Modeling, 3rd edn. Academic Press: San Diego.

Toyama Prefecture. 1976. The Scientific Assessment Report on TateyamaKurobe area in Chubu-Sangaku National Park. Toyama Prefecture: Toyama (in Japanese).

Wada N, Kawada K, Kawamura R, Aoki K, Kume A. 2004. Increasing winter runoff in a middle-latitude mountain area of central Japan. Journal of the Meteorological Society of Japan 82: 1589-1597.

Walter MT, Brooks ES, McCool DK, King LG, Molnau M, Boll J. 2005. Process-based snowmelt modeling: does it require more input data than temperature-index modeling? Journal of Hydrology 300: 65-75. DOI: 10.1016/j.jhydro.2004.05.002.

Westmacott JR, Burn DH. 1997. Climate change effects on the hydrologic regime within the Churchill-Nelson River Basin. Journal of Hydrology 202: 263-279. DOI: 10·1016/S0022-1694(97)00073-5.

Whitaker AC, Sugiyama H. 2005. Seasonal snowpack dynamics and runoff in a cool temperate forest: lysimeter experiment in Niigata, Japan. Hydrological Processes 19: 4179-4200. DOI: 10.1002/hyp.6059.

Yamazaki T, Taguchi F, Kondo J. 1994. Estimation of the heat balance in a small snow covered forested catchment basin. Tenki 41: 71-77 (in Japanese).

Yoshifuji N, Kumagai T, Tanaka K, Tanaka N, Komatsu H, Suzuki M, Tantasirin C. 2006. Inter-annual variation in growing season length of a tropical seasonal forest in northern Thailand. Forest Ecology and Management 229: 333-339. DOI: 10·1016/j.foreco.2006·04-013.

Zhang Y, Suzuki K, Kadota T, Ohata T. 2004. Sublimation from snow surface in southern mountain taiga of eastern Siberia. Journal of Geophysical Research 109: D21103. DOI: 10·1029/2003JD003779.

Zierl B, Bugmann H. 2005. Global change impacts on hydrological processes in Alpine catchments. Water Resources Research 41 W02028. DOI: 10·1029/2004WR003447. 